\title{
TRÊS DÉCADAS DE PESQUISA EM EMPREENDEDORISMO: UMA REVISÃO DOS PRINCIPAIS PERIÓDICOS INTERNACIONAIS DE EMPREENDEDORISMO
}

\author{
*Manuel Portugal Vasconcelos Ferreira \\ manuel.portugal.ferreira@gmail.com
}

\author{
**Cláudia Frias Pinto \\ claudia.frias.pinto@gmail.com
}

*Rui Mourato Miranda

rmiranda@portugalmail.pt

*Instituto Politécnico de Leiria, Leiria / Portugal
**Fundação Getúlio Vargas - São Paulo, SP / Brasil

http://dx.doi.org/10.1590/1413-2311.0342014.52536

Recebido em 29/072014

Aprovado em 16/07/2015

Disponibilizado em 01/08/2015

Avaliado pelo sistema "double blind review"

Revista Eletrônica de Administração

Editor: Luís Felipe Nascimento

ISSN 1413-2311 (versão "on line")

Editada pela Escola de Administração da Universidade Federal do Rio Grande do Sul.

Periodicidade: Quadrimestral

Sistema requerido: Adobe Acrobat Reader.

\section{RESUMO}

A pesquisa acadêmica em empreendedorismo tem crescido substancialmente durante as últimas três décadas, em parte aplicando teorias e constructos de outras disciplinas, e em parte desenvolvendo sobre o seu próprio objeto de estudo. Neste artigo realizamos um estudo bibliométrico em oito periódicos líderes na pesquisa em empreendedorismo, para captar um panorama geral e estrutural do conhecimento acumulado. Metodologicamente, analisamos autores mais prolíficos e nacionalidades, citações e obras com maior impacto, cocitações para entender a estrutura intelectual do campo e temas pesquisados para entender o foco da pesquisa. As análises incidiram sobre uma amostra de 1.414 artigos publicados ao longo de trinta anos, de 1981 a 2010. Os resultados mostram o crescimento da pesquisa em empreendedorismo, o predomínio claro da academia Norte Americana, que a pesquisa em empreendedorismo é bastante eclética relativamente às teorias e fenômenos examinados, integrando as principais teorias de Administração, e permitem examinar a estrutura intelectual que relaciona trabalhos e teorias. Destaca-se o trabalho de Schumpeter (1934) como o mais citado e cinco principais temas que pesquisados: 'Entrepreneurial process', 'Environmental and external determinants of entrepreneurship', 'Methods, theories and research issues', 'Value creation and performance' e 'Psychological, cognitive and individual characteristics'. Concluímos apontando áreas e tópicos que merecem a atenção de acadêmicos para pesquisa futura.

Palavras-Chave: estudo bibliométrico; empreendedorismo; revisão literatura; tendências na pesquisa

REAd | Porto Alegre - Edição 81 - No 2 - maio/agosto 2015 - p 406 - 436 
Manuel Portugal Vasconcelos Ferreira, Cláudia Frias Pinto \& Rui Mourato Miranda

\title{
THREE DECADES OF ENTREPRENEURSHIP RESEARCH: A REVIEW OF THE
}

\section{HIGHER STATURE INTERNATIONAL JOURNALS ON ENTREPRENEURSHIP}

\begin{abstract}
Entrepreneurship research has soared over the last three decades, partly based on applying theories and constructs from other disciplines and partly delving into its own object of study. In this paper we conduct a bibliometric study on eight top ranked journals for entrepreneurship research to capture a broad view and the structure of accumulated knowledge. Methodologically, we analyze most prolific authors and nationalities, citations and works with higher impact, co-citations to understand the intellectual structure of the field, and the themes researched, to understand the focus of research. The analyses used a sample of 1.414 articles published over a thirty years period, from 1981 to 2010 . Results show the growth in entrepreneurship research, that North American academy has been prominent, that entrepreneurship research has been largely eclectic concerning the theories and phenomena examined, integrating the main management theories, and permit us examine the intellectual structure binding works and theories. Schumpeter (1934) is the most cited work and five research themes have captured more attention: 'Entrepreneurial process', 'Environmental and external determinants of entrepreneurship', 'Methods, theories and research issues', 'Value creation and performance' e 'Psychological, cognitive and individual characteristics'. We conclude pointing areas and topics that warrant scholars' attention for future research.
\end{abstract}

Keywords: bibliometric study; entrepreneurship; literature review; research trends.

\section{TRES DÉCADAS DE PESQUISA EN EMPRENDEDURISMO: UNA REVISIÓN DE LOS PRINCIPALES PERIÓDICOS INTERNACIONALES DE EMPRENDEDURISMO}

\begin{abstract}
RESUMEN
La pesquisa académica en emprendedurismo ha crecido substancialmente durante las ultimas tres décadas, en parte aplicando teorías y constructos de otras disciplinas, y en parte desarrollado sobre su propio objeto de estudio. En este articulo hicimos un estudio bibliométrico en ocho periódicos líderes en la pesquisa en emprendedurismo, para captar un panorama general y estructural de conocimiento acumulado. Metodológicamente, analizamos los autores más prolíficos y nacionalidades, citas bibliográficas y obras con mayor impacto, co-citas, para entender la estructura intelectual del campo y temas buscados para entender el objeto de la pesquisa. Las análisis se hicieron sobre una muestra de 1.414 artículos publicados a lo largo de treinta años, de 1981 a 2010. Los resultados indican un crecimiento da pesquisa em emprendedurismo, lo dominio evidente de la academía Estadounidense, que la pesquisa en emprendedurismo es muy ecléctica relativamente a las teorías e fenómenos examinados, integrando las principales teorías de gestión, y permiten examinar la estructura intelectual que conecta trabajos e teorías. Schumpeter (1934) es lo mas citado y cinco temas mas pesquisados: 'Entrepreneurial process', 'Environmental and external determinants of entrepreneurship', 'Methods, theories and research issues', 'Value creation and performance' e 'Psychological, cognitive and individual characteristics'. Concluimos indicando áreas y tópicos que meritan la atención de académicos para pesquisas futuras.

Palabras Clave: estudio bibliométrico; emprendedurismo; revisión de literatura; tendencias en la pesquisa
\end{abstract}

REAd | Porto Alegre - Edição 81 - No 2 - maio/agosto 2015 - p 406 - 436 
TRÊS DÉCADAS DE PESQUISA EM EMPREENDEDORISMO: UMA REVISÃO DOS PRINCIPAIS PERIÓDICOS INTERNACIONAIS DE EMPREENDEDORISMO

\section{INTRODUÇÃO}

A pesquisa em empreendedorismo tem aumentado substancialmente nos últimos trinta anos, e em especial desde a revisão do estado do conhecimento por Low e MacMillan (1988) em que apontaram linhas para pesquisa futura. Apesar do crescente interesse por empreendedorismo, a disciplina, enquanto campo acadêmico, ainda padece das usuais críticas e questionamentos sobre se há realmente uma disciplina específica de empreendedorismo que a distingue de outros estudos em Administração. O fato é que empreendedorismo tem atraído mais atenção, como é revelado no surgimento de novos periódicos acadêmicos dedicados (como o Strategic Entrepreneurship Journal, em 2007, e no Brasil a REGEPE, em 2012), além de artigos e números especiais publicados em periódicos de elevada reputação como o Academy of Management Review, Strategic Management Journal e Academy of Management Executive, dentre outros. Acompanhando o crescente interesse de acadêmicos, a disciplina tem ganho contribuições de diversas áreas e de pesquisadores que trazem novas e diversas perspectivas teóricas, para o estudo de uma diversidade de assuntos específicos ao empreendedorismo (BUSENITZ ET AL., 2003; CAMPOS ET AL., 2012).

Neste artigo, analisamos o histórico da pesquisa em empreendedorismo. Esta revisão do estoque de conhecimento acumulado é importante para o desenvolvimento futuro da pesquisa. Periodicamente, os acadêmicos beneficiam de análises que sintetizam e sumariam o conhecimento existente e, eventualmente, apontam direções de pesquisa futura. No caso da disciplina de empreendedorismo, estes levantamentos periódicos são talvez mais pertinentes pela diversidade que a caracteriza. É possível que esta diversidade conceitual e de objetos de estudo se prendam com a complexidade disciplinar em formar um corpus único e distintivo em empreendedorismo porque confluem desde os recursos humanos, as finanças, as questões técnicas e culturais, até as mais comportamentais, de marketing e, inclusive, de negócios internacionais, no qual ganha corpo o empreendedorismo internacional.

Neste artigo, visamos entender a pesquisa publicada - num conjunto dos melhores periódicos internacionais em empreendedorismo - ao longo dos últimos trinta anos. Com este estudo, ao examinar os principais autores, obras e temas numa comunidade acadêmica, ganhamos uma compreensão da evolução da pesquisa, da sua estrutura social, e entendemos a estrutura das ligações intelectuais que ligam teorias, temas e autores na pesquisa existente (WHITE; MCCAIN, 1998; RAMOS-RODRIGUEZ; RUIZ-NAVARRO, 2004), a partir da qual podemos discutir pesquisa futura. Compreender a pesquisa já realizada numa área ainda relativamente jovem como é empreendedorismo (LOW, 2001) é especialmente importante 
para acadêmicos, e permite não apenas conhecer o que já foi, e como, pesquisado, os principais autores, e como as teorias se relacionam. Este estudo é, também, uma referência para identificar lacunas e rumos para pesquisas futuras (CHABOWSKY ET AL., 2010). É, assim, um documento, especialmente útil para estudantes de Mestrado e Doutorado, e pesquisadores recentemente chegados ao campo de empreendedorismo.

Metodologicamente, realizamos um estudo bibliométrico sobre 1.414 artigos publicados em oito periódicos líderesem empreendedorismo, ao longo de um período de trinta anos - de 1981 a 2010. A seleção dos periódicos foi feita com base na classificação de Harzing (2011), por terem maiores fatores de impacto, e pela sua reputação para a publicação de pesquisa em empreendedorismo (SCHILDT ET AL. 2006; LANDSTRÖM ET AL. 2012; BUSENITZ ET AL. 2014). As análises bibliométricas visaram a construção de um panorama descritivo de nacionalidades e autores prolíficos e principais obras. Em seguida, as análises de citações permitiram identificar as principais obras e que, presumivelmente, tiveram maior impacto no campo. As redes de cocitações serviram para identificar a estrutura intelectual, ou seja, como as obras se relacionam. Por fim, classificamos e observamos quais foram os principais temas pesquisados durante as últimas décadas.

A contribuição deste trabalho é iminentemente acadêmica, na medida em que, em essência, revemos literatura. No entanto, usamos os resultados para entender o estado atual da pesquisa realizada, a partir da qual podemos discutir o estado de maturidade da disciplina e extrapolar potenciais pistas para pesquisas futuras. Este tipo de levantamento da literatura é relevante para pesquisadores, por permitir entender a estrutura intelectual da pesquisa na disciplina, identificar os trabalhos com maior influência e como toda a área se interconecta. Este estudo complementa, assim, outras revisões de literatura e estudos bibliométricos e cientométricos existentes (LOW e MACMILLAN, 1988; CAMPOS ET AL., 2012; LANDSTRÖM; HARIRCHI e ASTRÖM, 2012; FERREIRA ET AL., 2014), ao aplicar técnicas de análises diferenciadas e um período de tempo mais alargado.

$\mathrm{O}$ artigo está estruturado em quatro partes. Na primeira parte, revemos o fundamental das fundações conceituais. Na segunda, descrevemos os procedimentos e amostra usados neste estudo. E em seguida os resultados das análises bibliométricas. Concluímos com uma ampla discussão apontando limitações e, fundamentalmente, sintetizando o estoque de conhecimento e vias para pesquisa futura.

\section{FUNDAÇÕES CONCEITUAIS DOS ESTUDOS BIBLIOMÉTRICOS}

REAd | Porto Alegre - Edição 81 - N 2 - maio/agosto 2015 - p 406 - 436 
TRÊS DÉCADAS DE PESQUISA EM EMPREENDEDORISMO: UMA REVISÃO DOS PRINCIPAIS PERIÓDICOS INTERNACIONAIS DE EMPREENDEDORISMO

O embasamento conceitual das redes sociais (SMALL, 1973; WASSERMAN; FAUST, 1994; FREEMAN, 2011) sustenta as principais análises bibliométricas que realizamos, observando-se como se interconectam teorias e temas de pesquisa. Perspectivas baseadas em análises de redes sociais têm sido populares para analisar estruturas sociais e padrões na geração de conhecimento científico (HARGENS, 2000). Observando a produção científica por meio de teoria das redes sociais, as estruturas sociais emergem como redes de trabalhos mais influentes, que se relacionam pelas citações e cocitações. Forma-se, no agregado, o domínio científico do campo, que conseguimos visualizar numa rede. Essa rede é passível de ser analisada olhando e mensurando a composição das redes, a força dos laços e a estrutura, com trabalhos mais centrais e outros mais periféricos, com teorias mais fortemente conectadas e outras com laços mais tênues. A ênfase das análises de redes sociais está em determinar quais e como os trabalhos se relacionam, e como formam laços mais fortes ou mais fracos entre si, ou como formam clusters (CHABOWSLY ET AL., 2010). Na literatura de redes sociais referimo-nos à coesão que é obtida pela análise das redes de cocitações, identificandose a frequência com que os trabalhos são juntamente citados num outro (MCCAIN, 1986). A força destes laços evidencia uma ligação conceitual mais forte.

Os estudos bibliométricos utilizam uma variedade de fontes documentais para analisar o conhecimento num dado campo, como livros, artigos científicos, teses e dissertações, dentre outros. A vantagem em utilizar apenas os artigos publicados é que estes foram validados pelos pares no usual processo de double bind review (ver RAMOS-RODRIGUEZ e RUÍZNAVARRO, 2004), sendo considerados conhecimento certificado. As análises bibliométricas assentam em procedimentos estatísticos e matemáticos que viabilizam analisar grandes volumes de dados, não possíveis com observações qualitativas ou de conteúdo. Os estudos bibliométricos, segundo Diodato (1994), Daim et al. (2006) e Ferreira (2011) permitem examinar uma variedade de assuntos para ajudar a entender, organizar e explorar o que já foi feito, ou pesquisado. Por exemplo, identificar as relações entre autores da área (CORNELIUS; LANDSTRÖM; PERSSON, 2006; GARTNER ET AL., 2006), quais os tópicos ou temas chave da área (CULNAN, 1987; SCHILDT ET AL., 2006; FURRER; TOMAS; GOUSSEVSKAIA, 2008), quais os trabalhos com maior impacto no campo (RATNATUNGA; ROMANO, 1997; LANDSTRÖM ET AL., 2012) e extrapolar sobre o seu impacto na disciplina, e encontrar relações intelectuais de proximidade entre as obras de maior relevância na área (WHITE; MCCAIN, 1998). Segundo Chen (2004), os estudos bibliométricos são úteis não apenas para entender o que tratou a pesquisa realizada, mas

REAd | Porto Alegre - Edição 81 - N 2 - maio/agosto 2015 - p 406 - 436 
Manuel Portugal Vasconcelos Ferreira, Cláudia Frias Pinto \& Rui Mourato Miranda

também para identificar as suas fronteiras atuais e, segundo Chabowsky et al. (2010), inferir desse levantamento qual a pesquisa futura.

A realização de estudos bibliométricos tem-se tornado mais comum nas diversas disciplinas de Administração (NEDERHOF ET AL., 2005; CHIU; HO, 2007; ANDRES, 2009). Por exemplo, em estratégia Phelan, Ferreira e Salvador (2002) examinaram todo o histórico de publicações no Strategic Management Journal (SMJ) para identificar tipos de artigos, autorias, tempo para publicação e amostras. Ramos-Rodríguez e Ruíz-Navarro (2004) analisaram os artigos publicados no SMJ para identificar a estrutura intelectual da disciplina. Em Negócios Internacionais, Ferreira (2011) e Ferreira et al. (2012) analisaram o impacto de um autor e de uma obra, respectivamente, na investigação realizada, por meio de análises de citações, cocitações e coocorrências. Mas, estudos bibliométricos já foram realizados em diversas outras disciplinas como sistemas de informação (CULNAN, 1987), pesquisa do consumidor (HOFFMAN; HOLBROOK, 1993), publicidade (PASADEOS ET AL., 1998), gestão de operações (PILKINGTON; LISTON-HEYES, 1999), gestão do conhecimento (PONZI, 2002) e contabilidade (CHUN ET AL., 1992). Vários destes estudos assentam em análises de cocitações como forma de esclarecer a estrutura social da pesquisa no campo (RAMOS-RODRIGUEZ; RUIZ-NAVARRO, 2004; SMALL; GRIFFITH, 1974; DÉRY; TOULOUSE, 1996) e mapear as áreas de pesquisa (WHITE; GRIFFITH, 1981).

Em empreendedorismo identificamos diversos estudos de revisão da literatura, usando metodologias distintas e com objetivos também diferentes. Shane (1997) analisou o impacto de autores na pesquisa em empreendedorismo observando o número de publicações em periódicos de alta reputação. Déry e Toulouse (1996) examinaram os artigos publicados em um único periódico, o Journal of Business Venturing, para identificar a estrutura intelectual da área. Campos et al. (2012) estudaram uma amostra de artigos para entender quais os temas principais na pesquisa em empreendedorismo e como estes se relacionam. Ratnatunga e Romano (1997), numa análise dos artigos mais citados observaram os temas pesquisados e concluíram pelo predomínio de estudos sobre as características do empreendedor. Fried (2003) identificou os periódicos de maior impacto em empreendedorismo. Grégoire et al. (2006) examinaram as redes de cocitações concluindo sobre a evolução dos temas de pesquisa ao longo do tempo, entre 1981 e 2004. Também Schildt et al. (2006) se debruçaram sobre a identificação de temas de pesquisa. Landström et al. (2012), fizeram uma análise bibliométrica usando referências de 12 handbooks de empreendedorismo e identificaram os 
produtores de conhecimento que mais contribuíram para a pesquisa em empreendedorismo, assim como os trabalhos de maior impacto na disciplina.

\section{MÉTODO}

\subsection{Amostra}

Os procedimentos para a identificação da amostra envolveram duas etapas. A primeira etapa consistiu na seleção dos periódicos a analisar, para o que recorremos à Journal Quality List, de Ann-Will Harzing, edição 38, de 2011, aos fatores de impacto (ver Tabela 1) e à seleção de periódicos inclusos em outros estudos bibliométricos existentes (FRIED, 2003; KATZ 2003; SCHILDT ET AL. 2006; LANDSTRÖM ET AL. 2012; BUSENITZ ET AL. 2014, JING ET AL. 2014). Incluímos o Strategic Entrepreneurship JournaI (SEJ), porque embora tenha sido fundado em 2007, e tenha um histórico curto de artigos publicados, já possui um fator de impacto á 5 anos de 3,518, próximo do Journal of Business Venturing (com 3,914), Entrepreneurship Theory and Practice (3,839) e Journal of Product Innovation Management (3,626). Este periódico contribuiu com 61 artigos para o total da nossa amostra. Nota-se que estes periódicos são relativamente recentes, e apenas o Journal of Product Innovation Management existe desde 1984.

Tabela 1 - Os periódicos na amostra e fatores de impacto

\begin{tabular}{|c|c|c|c|}
\hline Journal & $\begin{array}{c}\text { Fator } \\
\text { de } \\
\text { impacto } \\
\text { a } 5 \text { anos }\end{array}$ & $\begin{array}{c}\text { Fator } \\
\text { de } \\
\text { impacto }\end{array}$ & $\begin{array}{c}\mathbf{N}^{\mathbf{o}} \text { total } \\
\text { de } \\
\text { citações }\end{array}$ \\
\hline Journal of Business Venturing & 3,914 & 2,149 & 3.202 \\
\hline Entrepreneurship Theory and Practice & 3,839 & 2,272 & 2.346 \\
\hline Journal of Product Innovation Management & 3,626 & 2,079 & 2.472 \\
\hline Strategic Entrepreneurship Journal & 3,518 & 2,026 & 249 \\
\hline Small Business Economics & 2,057 & 1,555 & 1.560 \\
\hline Entrepreneurship and Regional Development & 1,770 & 1,353 & 688 \\
\hline International Small Business Journal & 1,748 & 0,927 & 582 \\
\hline Journal of Small Business Management & 1,703 & 1,189 & 1.043 \\
\hline
\end{tabular}

Os artigos publicados nos periódicos líderes proporcionam a oportunidade para generalizar a pesquisa no campo (CHABOWSKY ET AL., 2010). Presumivelmente, os periódicos mais conceituados publicam a pesquisa com maior potencial de impacto, e são os mais procurados pelos pesquisadores, quer para publicarem os seus artigos, quer para identificarem referências relevantes para citarem nos seus trabalhos. Assim, esses oito 
Manuel Portugal Vasconcelos Ferreira, Cláudia Frias Pinto \& Rui Mourato Miranda

periódicos permitem-nos obter uma amostra representativa da pesquisa de maior relevância em empreendedorismo.

A segunda etapa na construção da amostra envolveu a identificação dos artigos na ISI Web of Knowledge, no motor de busca Web of Science. Essa base foi usada em diversas pesquisas anteriores (RAMOS-RODRIGUEZ; RUIZ-NAVARRO, 2004; SCHILDT ET AL., 2006; FURRER ET AL., 2008; FERREIRA, 2011) e, é reconhecida como de maior prestígio. Na definição das palavras-chave para realizar a busca no ISI web of knowledge, seguimos as indicações de Busenitz et al. (2003) sobre os possíveis termos de pesquisa em empreendedorismo. Assim, utilizamos como termos de pesquisa: entrepreneur, entrepreneurial, entrepreneurship, small business, new ventures e founders. Estes termos de pesquisa (usualmente referidos como keywords ou palavras-chave) foram colocados no campo de seleção "Topic" do motor de busca. A amostra final do nosso estudo ficou constituída por 1.414 artigos nos oito periódicos (Tabela 2), no qual se destaca a contribuição de dois periódicos, o JBV (cerca de $30 \%)$ e o SBE (23\%).

Tabela 2 - A composição da amostra por periódico

\begin{tabular}{|c|c|c|c|c|c|}
\hline Nome do periódico & $\begin{array}{c}\mathrm{N}^{\mathbf{0}} \text { de } \\
\text { artigos } \\
\text { na } \\
\text { amostra } \\
\end{array}$ & $\begin{array}{l}\mathrm{N}^{\circ} \text { total de } \\
\text { artigos } \\
\text { publicados }\end{array}$ & $\begin{array}{l}\text { Primeiro } \\
\text { ano } \\
\text { acessível }\end{array}$ & $\begin{array}{c}\% \text { da } \\
\text { amostra } \\
(1.414)\end{array}$ & \\
\hline Journal of Business Venturing (JBV) & 420 & 781 & 1987 & 29,70 & \\
\hline Small Business Economics (SBE) & 326 & 970 & 1992 & 23,06 & $\boldsymbol{n}$ \\
\hline $\begin{array}{l}\text { Journal of Small Business Management } \\
\text { (JSBM) }\end{array}$ & 192 & 518 & 1995 & 13,58 & u \\
\hline $\begin{array}{l}\text { Entrepreneurship Theory and Practice } \\
\text { (ETP) }\end{array}$ & 171 & 361 & 2003 & 12,10 & $\boldsymbol{\square}$ \\
\hline $\begin{array}{l}\text { Entrepreneurship and Regional } \\
\text { Development (ERD) }\end{array}$ & 120 & 247 & 2001 & 8,49 & $\mathbf{a}$ \\
\hline $\begin{array}{l}\text { International Small Business Journal } \\
\text { (ISBJ) }\end{array}$ & 96 & 369 & 2003 & 6,78 & $\mathbf{\square}$ \\
\hline Strategic Entrepreneurship Journal (SEJ) & 61 & 102 & 2007 & 4,31 & च \\
\hline $\begin{array}{l}\text { Journal of Product Innovation } \\
\text { Management (JPIM) }\end{array}$ & 28 & 1425 & 1984 & 1,98 & I \\
\hline
\end{tabular}

Nota: Ano refere-se ao primeiro período em que os artigos foram disponibilizadosna ISI web of knowledge Fonte: dados coletados da ISI - Web of Knowledge. Cálculos dos autores.

\subsection{Procedimentos de análise}

Os procedimentos seguidos foram baseadoss em três tipos de análises fundamentais: análise de citações, de cocitações e dos temas abordados nos artigos. Seguimos a proposta de Schildt, Zahra e Sillanpää (2006) para analisar a proximidade entre os trabalhos, a partir da qual inferimos a sua ligação intelectual. Também recorremos ao procedimento especificado 
TRÊS DÉCADAS DE PESQUISA EM EMPREENDEDORISMO: UMA REVISÃO DOS PRINCIPAIS PERIÓDICOS INTERNACIONAIS DE EMPREENDEDORISMO

por Furrer, Tomas e Goussevskaia (2009) sobre como utilizar as palavras-chave fornecidas pelos autores para agregar em grandes áreas temáticas que evidenciam os temas pesquisados. No entanto, para delimitar inicialmente os temas seguimos o trabalho de Schildt et al. (2006).

Análise de citações. A citação a trabalhos existentes é uma norma estabelecida na escrita acadêmica. A racionalidade subjacente à análise de contagem de citações é que, os acadêmicos, na realização das suas pesquisas e escrita de artigos, citam outros documentos que contribuem para o seu próprio trabalho (RAMOS-RODRIGUEZ; RUÍZ-NAVARRO, 2004). Assim, a frequência de citações é comumente utilizada como métrica de impacto na área (CULNAN, 1987; PASADEOS ET AL., 1998; TAHAI; MEYER, 1999; RAMOSRODRIGUEZ; RUÍZ-NAVARRO, 2004).

Análise de cocitações. Esta análise assenta na identificação da frequência com que pares de artigos são citados em conjunto, ou cocitados, em outros trabalhos (CULNAN, 1987). A análise de cocitações exige que observemos as listas de referências para inferir algum tipo de semelhança, conexão, ou proximidade intelectual (PILKINGTON; LISTONHEYES, 1999; PONZI, 2002; ROKAYA ET AL., 2008; CHABOWSKI ET AL., 2010; HOFER ET AL., 2010), seja de objeto ou conceitual. Assim, temos a assunção que dois artigos que são frequentemente cocitados serão relativamente próximos intelectualmente (WHITE; GRIFFITH, 1981; WHITE; MCCAIN, 1998; RAMOS-RODRIGUEZ; RUIZNAVARRO, 2004). Por exemplo, Small e Griffith (1974) e White e Griffith (1981) analisaram as cocitações para mapear áreas e temas de pesquisa. Déry e Toulouse (1996) usaram cocitações para escrutinar a estrutura social da pesquisa numa amostra de trabalhos de empreendedorismo.

Análise dos temas pesquisados. $O$ terceiro procedimento objetivou identificar quais os temas que têm sido pesquisados e sua centralidade relativa na disciplina. Usualmente, a identificação dos temas requer alguma forma, possivelmente subjetiva, de análise de conteúdo, o que seria inviável numa amostra de 1.414 artigos. Assim, para aferir os temas, seguimos a proposta de Furrer et al. (2008) assente no agrupamento em categorias mais amplas das palavras-chave fornecidas pelos autores dos artigos. As categorias, divididas em 25 temáticas, foram extraídas de Schildt, Zahra e Sillanpaa (2006) que definiram um conjunto de áreas fulcrais em empreendedorismo. Em seguida, dois bolsistas, separadamente, supervisionados pelo pesquisador principal, atribuíram cada palavra-chave às 25 categorias previamente estabelecidas (ver Anexo). Esta análise usou 2.791 palavras-chave, porque a ISI Web of Knowledge não contém as palavras-chave dos artigos publicados antes de 1993.

REAd | Porto Alegre - Edição 81 - No 2 - maio/agosto 2015 - p 406 - 436 
Manuel Portugal Vasconcelos Ferreira, Cláudia Frias Pinto \& Rui Mourato Miranda

Nas análises usaram-se dois softwares específicos. O Bibexcel, para extrair os dados bibliométricos dos artigos na amostra, como: nome do periódico, título, nomes dos autores, afiliações, resumos, palavras-chave e lista de referências. O software de redes sociais Ucinet, para a representação visual das redes, ou mapas relacionais e interconexões entre obras e temas pesquisados. Estes mapas, subsidiados nos dados bibliométricos são baseados em matrizes de coocorrências (BOYACK; BORNER, 2003; RAFOLS ET AL., 2010). Visualizar os dados bibliométricos como uma rede, permite mais facilmente identificar a estrutura subjacente a um grupo de trabalhos (BOYACK; BORNER, 2003; NEWMAN, 2003).

\section{RESULTADOS}

\subsection{Análise descritiva}

A figura 1 revela a tendência de crescimento da pesquisa em empreendedorismo, avaliado pelo número de artigos publicados e, de modo mais acentuado, a partir de 2002. É relevante notar que também tem aumentado o número de periódicos especializados, de pesquisadores, centros de pesquisa, e de programas de pós-graduação voltados para o empreendedorismo. O periódico incluso na ISI há mais tempo é o Journal of Product Innovation Management, desde 1984, seguido pelo Journal of Business Venturing (1987), Small Business Economics (1992), e o Journal of Small Business Management (1995), e os restantes são já da década de 2000, como o Entrepreneurship and Regional Development (2001), Entrepreneurship Theory and Practice (2003), International Small Business Journal (2003) e o mais recente Strategic Entrepreneurship Journal (2007). Essa emergência de novos periódicos evidencia que a disciplina ainda está na adolescência (LOW, 2001) ou maturação (BUSENITZ ET AL., 2003), mas ajuda a explicar o crescimento da pesquisa publicada em anos mais recentes.

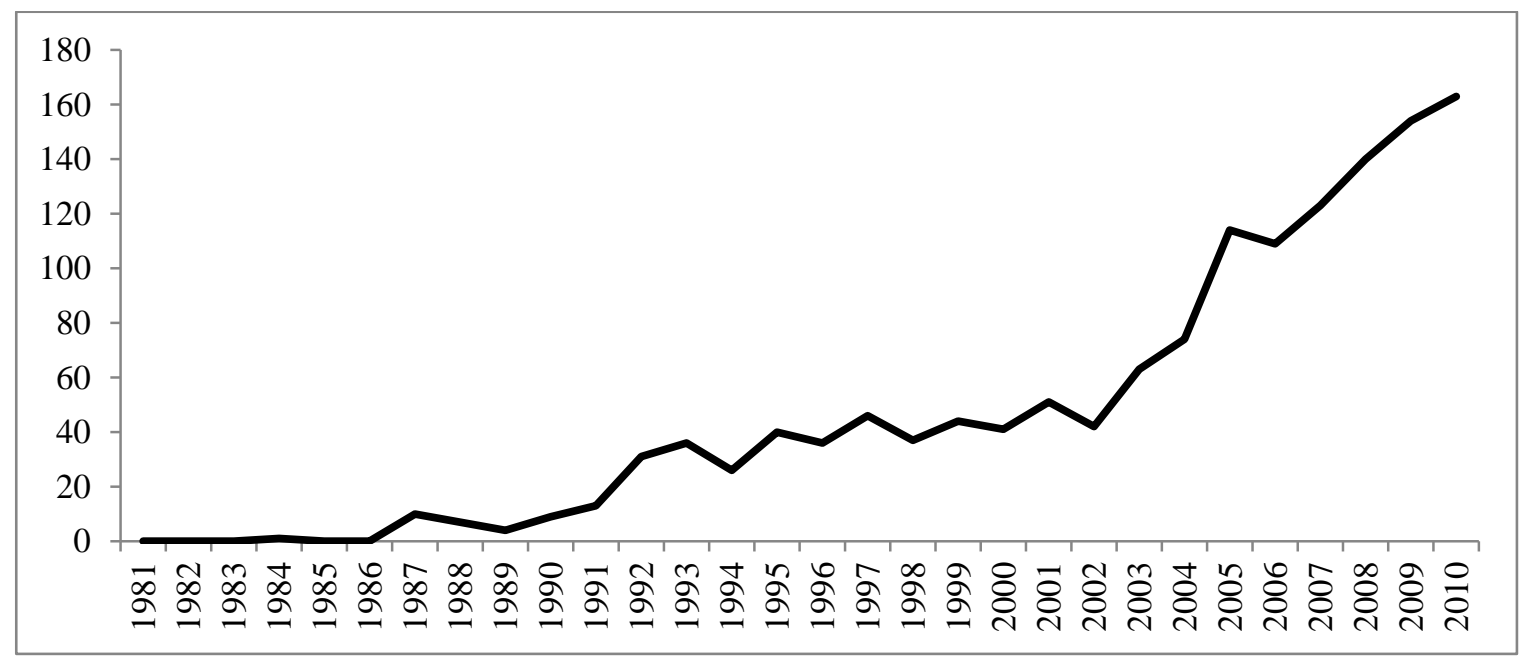

Figura 1 - Evolução longitudinal das publicações Fonte: dados da pesquisa coletados no ISI - Web of Knowledge.

REAd | Porto Alegre - Edição 81 - No 2 - maio/agosto 2015 - p 406 - 436 

PRINCIPAIS PERIÓDICOS INTERNACIONAIS DE EMPREENDEDORISMO

A tabela 3 mostra as nacionalidades de afiliação dos autores dos artigos. Alguns autores reportam mais que uma afiliação e nacionalidade da instituição. Talvez sem surpresa, os autores Norte-Americanos predominam, com 887 autorias ou coautorias (43,78\%), seguidos pelos ingleses (11\%) e canadenses (6\%). Assim, os países de língua inglesa estão no topo desta lista, o que também pode ser um resultado de autores estrangeiros terem uma desvantagens na língua inglesa, em comparação com os nativos na língua inglesa. Em alternativa, uma explicação plausível prende-se com o tema de empreendedorismo ter maior tradição nas universidades norte-americanas, porventura em virtude da própria cultura nacional, caracterizada pelo foco no sucesso individual (HOFSTEDE, 1980) e população empreendedora. As autorias de países emergentes são escassas, mas a China e Cingapura surgem em posições de topo neste ranking. Uma explicação está nos laços que pesquisadores na academia norte americana têm com acadêmicos nestes países e os elevados números de estudantes de doutorado da China, Cingapura e Coreia do Sul, nas universidades americanas.

Tabela 3 - Países com maior volume de publicações

\begin{tabular}{|c|c|c|c|c|c|}
\hline País & Art & $\%$ & País & Art & $\%$ \\
\hline EUA & 887 & 43,78 & Israel & 21 & 1,04 \\
\hline Inglaterra & 220 & 10,86 & Noruega & 20 & 0,99 \\
\hline Canadá & 117 & 5,77 & Nova Zelândia & 19 & 0,94 \\
\hline Alemanha & 91 & 4,49 & Suíça & 16 & 0,79 \\
\hline Holanda & 91 & 4,49 & Áustria & 13 & 0,64 \\
\hline Suécia & 57 & 2,81 & Grécia & 13 & 0,64 \\
\hline Austrália & 56 & 2,76 & Irlanda & 13 & 0,64 \\
\hline Escócia & 46 & 2,27 & Taiwan & 13 & 0,64 \\
\hline Espanha & 46 & 2,27 & Dinamarca & 12 & 0,59 \\
\hline Finlândia & 38 & 1,88 & Irlanda Norte & 10 & 0,49 \\
\hline Itália & 32 & 1,58 & Gales & 9 & 0,44 \\
\hline Bélgica & 28 & 1,38 & Coreia do Sul & 8 & 0,39 \\
\hline China & 28 & 1,38 & Turquia & 8 & 0,39 \\
\hline Cingapura & 26 & 1,28 & Japão & 6 & 0,30 \\
\hline França & 25 & 1,23 & África do Sul & 6 & 0,30 \\
\hline
\end{tabular}

As diferenças de produtividade acadêmica entre autores são consideráveis. A tabela 4, mostra os 50 autores mais prolíficos nestas oito revistas, dentre os 1.966 autores dos 1.414 artigos. No topo estão Wright (26 artigos), Shepherd (25), Zahra (19), Gartner (19), Westhead (17), Thurik e Chrisman (14), Acs e Ucbasaran (13) e Audretsch e Busenitz (12). Estes são autores amplamente reconhecidos na disciplina, e é razoável afirmar que os seus estudos têm um impacto significativo na direção que a pesquisa tem tomado. 
Manuel Portugal Vasconcelos Ferreira, Cláudia Frias Pinto \& Rui Mourato Miranda

Tabela 4 - Autores mais prolíficos

\begin{tabular}{|c|c|c|c|c|c|c|c|c|}
\hline Rank & Autor & Art & Rank & Autor & Art & Rank & Autor & Art \\
\hline 1 & Wright, M. & 26 & 18 & Reynolds, P. & 9 & 35 & Hmieleski, K. & 7 \\
\hline 2 & Shepherd, D. & 25 & 19 & Kuratko, D. & 9 & 36 & Parker, S. & 7 \\
\hline 3 & Zahra, S. & 19 & 20 & Sapienza, H. & 9 & 37 & Tan, J. & 7 \\
\hline 4 & Gartner, W. & 19 & 21 & Baron, R. & 9 & 38 & Chandler, G. & 7 \\
\hline 5 & Westhead, P. & 17 & 22 & Brush, C. & 9 & 39 & Deeds, D. & 7 \\
\hline 6 & Thurik, R. & 14 & 23 & Minniti, M. & 9 & 40 & Pearce, J. & 6 \\
\hline 7 & Chrisman, J. & 14 & 24 & De Clercq, D. & 9 & 41 & DeTienne, D. & 6 \\
\hline 8 & Acs, Z. & 13 & 25 & Cumming, D. & 9 & 42 & Miller, N. & 6 \\
\hline 9 & Ucbasaran, D. & 13 & 26 & Dana, L. & 9 & 43 & McMullan, W. & 6 \\
\hline 10 & Audretsch, D. & 12 & 27 & Bates, T. & 8 & 44 & Arenius, P. & 6 \\
\hline 11 & Busenitz, L. & 12 & 28 & Rosa, P. & 8 & 45 & Hornsby, J. & 6 \\
\hline 12 & Fiet, J. & 11 & 29 & Wong, $\mathrm{P}$. & 8 & 46 & Sarasvathy, S. & 6 \\
\hline 13 & Anderson, A. & 10 & 30 & Honig, B. & 8 & 47 & Chua, J. & 6 \\
\hline 14 & Covin, J. & 10 & 31 & Carree, M. & 8 & 48 & Slevin, D. & 6 \\
\hline 15 & Bruton, G. & 10 & 32 & Shane, S. & 8 & 49 & Greene, $\mathrm{P}$. & 6 \\
\hline 16 & McDougall, P. & 10 & 33 & van Stel, A. & 8 & 50 & Wiklund, J. & 6 \\
\hline 17 & Davidsson, P. & 10 & 34 & Levesque, M. & 7 & & & \\
\hline
\end{tabular}

Fonte: dados coletados na ISI Web of Knowledge usando o software Bibexcel. Cálculos dos autores.

\subsection{Análise de citações}

A análise de citações requer a identificação das obras de maior impacto. A Tabela 5 revela os 40 trabalhos mais citados, identificados entreas 40.789 referências totais utilizadas nos 1.414 artigos. No topo das citações está o trabalho de Joseph Schumpeter, de 1934, The theory of economic development. Nessa obra Schumpeter fez uma abordagem ao empreendedor e estabeleceu que aquele que empreende é o individuo que incute, de alguma forma, uma inovação. O segundo trabalho mais citado é a revisão de literatura de empreendedorismo, de Shane e Venkataraman (2000). É interessante notar que o trabalho de Jay Barney, sobre a Visão Baseada nos Recursos (ou Resource-based View), de 1991, surge em terceiro lugar, o que é evidência prima facie da penetração da VBR na pesquisa de empreendedorismo. Em seguida autores como Stinchcombe (1965), Kirzner (1973), Porter (1980), Venkataraman (1997), Penrose (1959), Storey (1994) e Low e MacMillan (1988). No conjunto, a diversidade de temas e teorias desta lista do top 40 é também evidência da multidisciplinaridade e diversidade que convivem na pesquisa em empreendedorismo (Campos et al., 2012). 
TRÊS DÉCADAS DE PESQUISA EM EMPREENDEDORISMO: UMA REVISÃO DOS PRINCIPAIS PERIÓDICOS INTERNACIONAIS DE EMPREENDEDORISMO

Tabela 5 - Os 40 trabalhos mais citados

\begin{tabular}{|c|c|c|c|c|c|}
\hline Rank & Obra & $\begin{array}{c}\text { Total } \\
\text { Cit } \\
\end{array}$ & Rank & Obra & $\begin{array}{c}\text { Total } \\
\text { Cit }\end{array}$ \\
\hline 1 & Schumpeter (1934) & 177 & 21 & Shane (2000) & 71 \\
\hline 2 & Shane \& Venkataraman (2000) & 165 & 22 & Nunnally (1978) & 68 \\
\hline 3 & Barney (1991) & 107 & 23 & Pfeffer \& Salancik (1978) & 67 \\
\hline 4 & Stinchcombe (1965) & 99 & 24 & Cohen \& Levinthal (1990) & 67 \\
\hline 5 & Kirzner (1973) & 97 & 25 & Miller (1983) & 66 \\
\hline 6 & Porter (1980) & 96 & 26 & Hair, Anderson, Tatham \& Black (1995) & 66 \\
\hline 7 & Venkataraman (1997) & 96 & 27 & Aldrich (1999) & 65 \\
\hline 8 & Penrose (1959) & 91 & 28 & Jensen \& Meckling (1976) & 65 \\
\hline 9 & Storey (1994) & 88 & 29 & Mcclelland (1961) & 64 \\
\hline 10 & Low \& MacMillan (1988) & 88 & 30 & Burt (1992) & 64 \\
\hline 11 & Gartner (1985) & 86 & 31 & Cooper, Gimeno-Gascon \& Woo (1994) & 64 \\
\hline 12 & Granovetter (1985) & 83 & 32 & Jovanovic (1982) & 64 \\
\hline 13 & Schumpeter (1942) & 82 & 33 & Aldrich \& Zimmer(1986) & 64 \\
\hline 14 & Eisenhardt (1989) & 77 & 34 & Granovetter (1973) & 63 \\
\hline 15 & Lumpkin \& Dess (1996) & 74 & 35 & Nelson \& Winter (1982) & 61 \\
\hline 16 & Knight (1921) & 74 & 36 & Birley (1985) & 61 \\
\hline 17 & Busenitz \&Barney (1997) & 74 & 37 & Covin \& Slevin (1989) & 60 \\
\hline 18 & Evans \& Jovanovic (1989) & 72 & 38 & Stevenson \& Jarillo (1990) & 57 \\
\hline 19 & Vesper (1990) & 71 & 39 & Gartner (1988) & 54 \\
\hline 20 & Evans \& Leighton (1989) & 71 & 40 & Gimeno, Folta, Cooper \& Woo (1997) & 54 \\
\hline
\end{tabular}

Da tabela observa-se que os trabalhos mais citados tendem a ser mais antigos. Por exemplo, o trabalho de Schumpeter (1934) é a principal referência, seguido por outros, como Shane e Venkataraman (2000), Barney (1991), Stinchcombe (1965), Kirzner (1973), Porter (1980), Venkataraman (1997), Penrose (1959), Storey (1994) e Low e MacMillan (1988). Ou seja, a maioria tem mais de duas décadas. Porquanto, é esperado que trabalhos mais antigos tenham mais citações,observa-se também quenão há evidências que trabalhos mais recentes estejam a ganhar proeminência, pelo menos de modo muito substancial.

\subsection{Análise de cocitações}

A figura 2 representa a rede de cocitações dos 40 artigos. Para ler a figura, note que o software Bibexcel posiciona os artigos na rede de acordo com a sua proximidade de cocitação. Assim, os trabalhos mais cocitados surgem no centro da rede e os menos cocitados são colocados na periferia da rede. Por exemplo, é notório que o trabalho de Schumpeter (1934), o mais central e presumivelmente com maior impacto, tem grande proximidade com o de Shane e Venkataraman (2000), ilustrando que muitos autores usam estes dois trabalhos, simultaneamente, nos seus próprios artigos. Observando outra seção da figura, identificamos, 
Manuel Portugal Vasconcelos Ferreira, Cláudia Frias Pinto \& Rui Mourato Miranda

por exemplo, os trabalhos de Shane (2000) contribuindo em aspetos de oportunidades empreendedoras, Knight (1921) sobre a percepção do risco e a incerteza nos novos negócios, e Kirzner (1973) aliando o empreendedorismo a aspetos de competitividade. Estes autores estão todos relativamente próximos entre eles significando que os temas de risco, incerteza, oportunidades empreendedoras e competitividade são relativamente próximos na pesquisa existente.

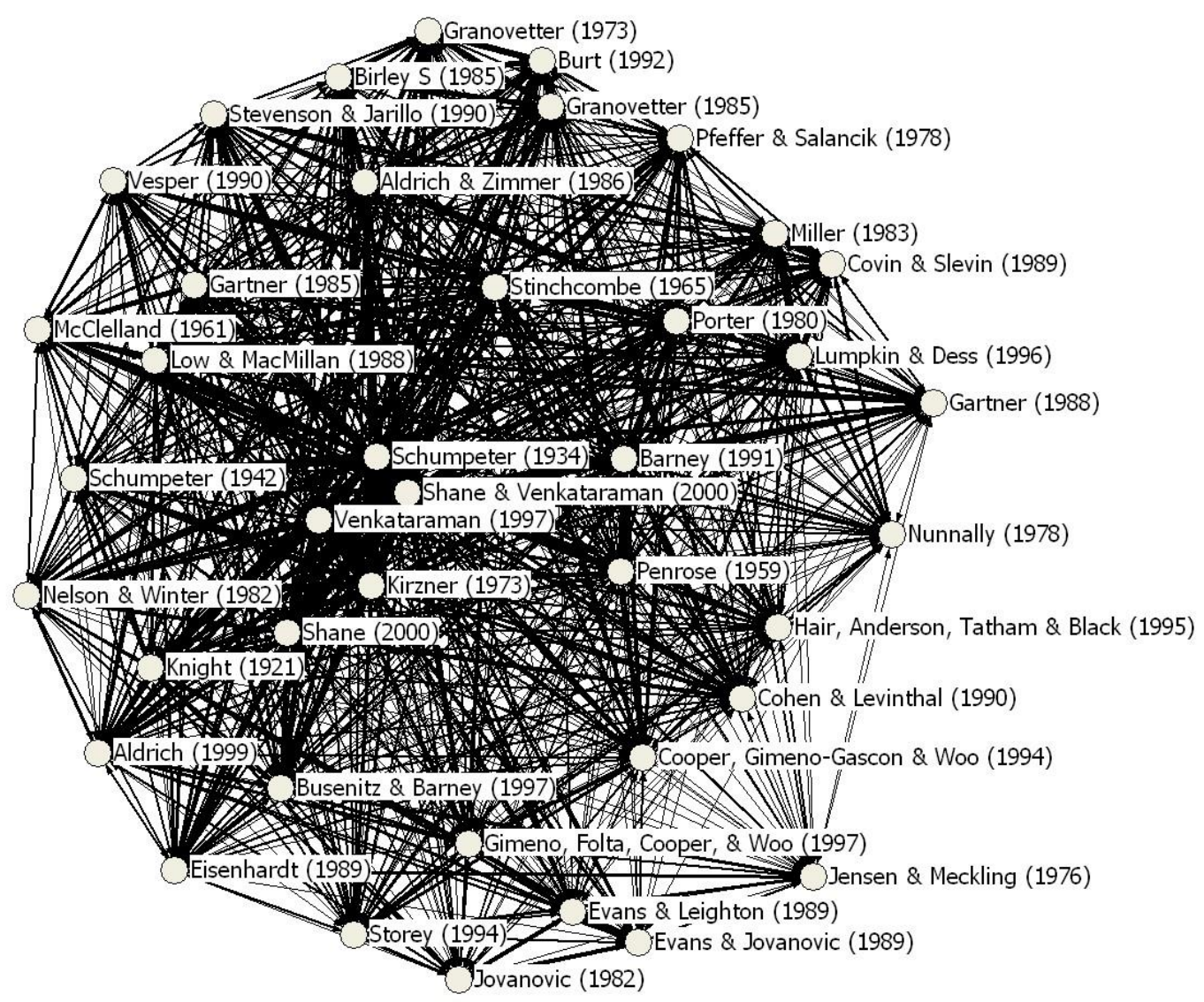

Figura 2 - Rede de cocitações dos trabalhos mais citados

Fonte: dados recolhidos do ISI - Web of Knowledge com o Bibexcel. Figura representada usando o Ucinet.

Outros trabalhos seminais em diferentes áreas de Administração têm sido referenciados na pesquisa em empreendedorismo, como os trabalhos de Porter (1980), Stinchcombe (1965), Penrose (1959), Nelson e Winter (1982) e Gartner (1985). A utilização de múltiplas abordagens conceituais pode ser vista como reveladora da relativa juventude da disciplina, que não parece ter ainda desenvolvido um corpo teórico próprio (SHANE; VENKATARAMAN, 2000). Essa observação concorda com algum debate que ainda existe sobre qual é o domínio de empreendedorismo como disciplina e se há um domínio específico.

\subsection{Análise dos temas pesquisados}

REAd | Porto Alegre - Edição 81 - N 2 - maio/agosto 2015 - p 406 - 436 
TRÊS DÉCADAS DE PESQUISA EM EMPREENDEDORISMO: UMA REVISÃO DOS PRINCIPAIS PERIÓDICOS INTERNACIONAIS DE EMPREENDEDORISMO

Finalmente, a análise dos temas de pesquisa foi, como explicado anteriormente, suportada na classificação das palavras-chave em 25 temas, seguindo os procedimentos de Furrer et al. (2008), com base nos sub-temas da área de empreendedorismo classificados por Schildt, Zahra e Sillanpaa (2006). Como alguns artigos não disponibilizavam na base as palavras-chave (ou keywords), essa análise utilizou as 2.791 disponíveis. A figura 3 mostra a rede relacional entre os temas e os seus posicionamentos relativos na rede. A interpretação deste mapa é idêntica à explanada para as cocitações. Com maior centralidade na rede surgem cinco temas mais pesquisados: 'Entrepreneurial process', 'Environmental and external determinants of entrepreneurship', 'Methods, theories and research issues', 'Value creation and performance' e 'Psychological, cognitive and individual characteristics'.

A espessura das linhas unindo os temas indica a frequência de coocorrência, de modo que linhas mais espessas revelam maior frequência. Por exemplo, o tema 'Entrepreneurial process' está mais conectado aos três temas 'Environmental and external determinants of entrepreneurship', 'Methods, theories and research issues' e 'Value creation and performance'. Genericamente, na periferia estão temas comparativamente menos pesquisados e com ligações mais fracas.

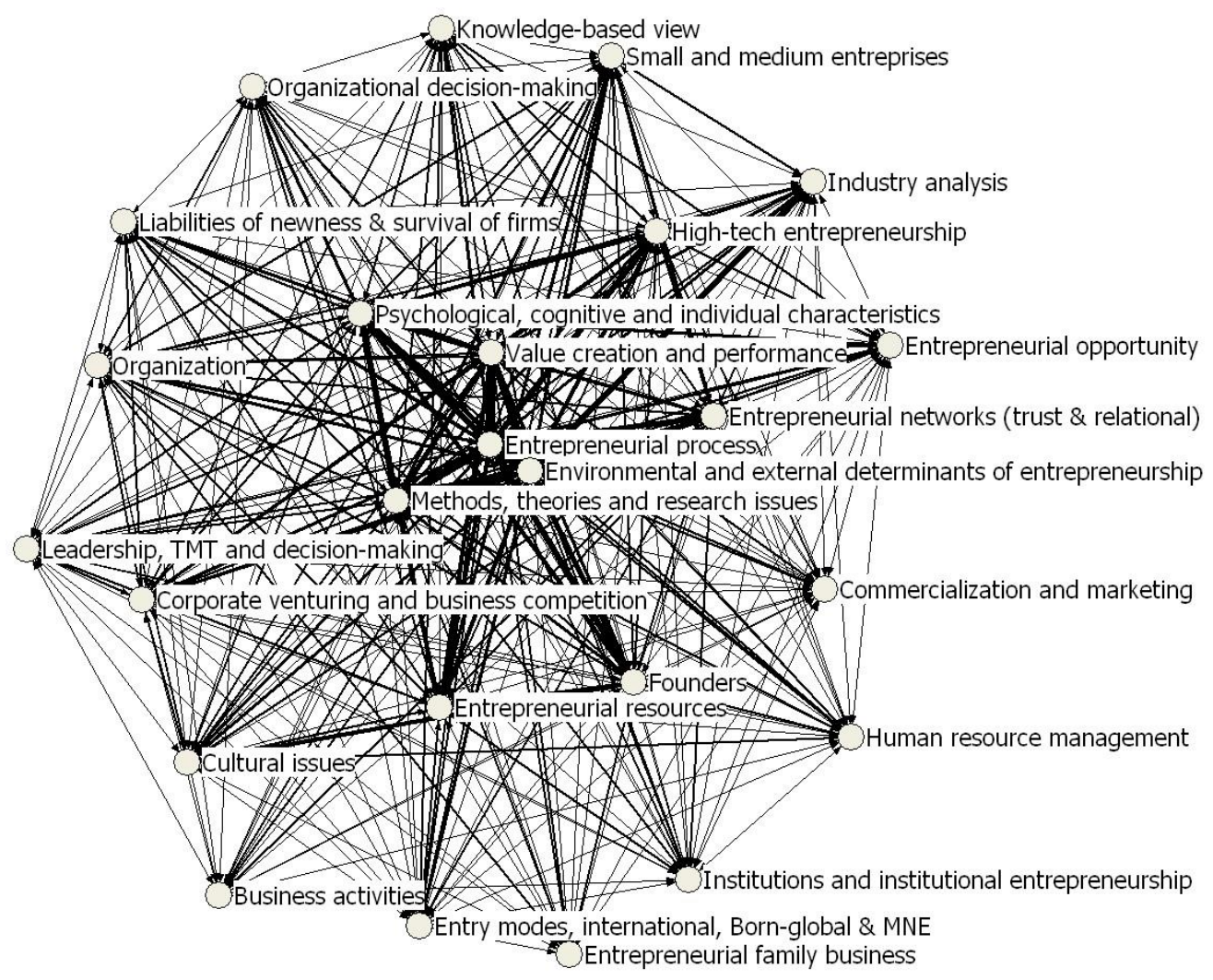

Figura 3 - Temas pesquisados

Fonte: dados recolhidos do ISI - Web of Knowledge e tratados com o Bibexcel. Rede representada usando o Ucinet. Ver lista dos temas em anexo.

REAd | Porto Alegre - Edição 81 - No 2 - maio/agosto 2015 - p 406 - 436 
Manuel Portugal Vasconcelos Ferreira, Cláudia Frias Pinto \& Rui Mourato Miranda

\section{DISCUSSÃO}

Neste artigo visámos entender a estrutura intelectual da pesquisa em empreendedorismo ao longo de um período de tempo de trinta anos, desde início dos anos 80, identificando obras de maior impacto, origem da pesquisa, redes de proximidade intelectual e temas pesquisados. $\mathrm{O}$ estudo, diferentemente de outros que se basearam em um período curto de tempo (BUSENITZ ET AL., 2014), num só periódico (FERREIRA ET AL., 2014) ou numa geografia delimitada (JING ET AL., 2014), utilizou mais de 1.400 artigos, em oito periódicos internacionais conceituados. Vale salientar que no Brasil há apenas um periódico especializado em empreendedorismo, o REGEPE, fundado em 2011. Este estudo complementa, assim, outros estudos de revisão de literatura sobre empreendedorismo existentes (SHANE, 1997; DÉRY; TOULOUSE, 1996; RATNATUNGA; ROMANO, 1997; FRIED, 2003; CAMPOS ET AL., 2012).

\subsection{Consolidação e pistas para o futuro da pesquisa em empreendedorismo}

Os dados relativos aos trabalhos mais citados (Tabela 5), à rede de cocitações (Figura 2) e dos temas (Figura 3) são especialmente interessantes ao revelar qual tem sido o foco da pesquisa.

Fundamentos teóricos. Na figura 2, no mapa de cocitações, observamos os trabalhos mais centrais na pesquisa existente denotando-se grande diversidade de abordagens conceituais ou teóricas, desde as redes relacionais (GRANOVETTER, 1973, 1985; BURT, 1982; ALDRICH; ZIMMER, 1986), visão baseada em recursos (PENROSE, 1959; BARNEY, 1991) e dependência de recursos (PFEFFER; SALANCIK, 1978), aprendizagem (COHEN; LEVINTHAL, 1990), ecologia populacional e o acesso inicial a recursos (COOPER ET AL., 1994) e a teoria da agência (JENSEN; MECKLING, 1976).

A emergência da Visão Baseada em Recursos (BARNEY, 1991) e Teoria da Dependência de Recursos (PFEFFER; SALANCIK, 1978) parece sustentar parte da pesquisa em quais são os recursos necessários ao empreendedor e nova empresa, não apenas complementando a ideia veiculada pela ecologia populacional de que os recursos no momento da fundação são cruciais, mas também mostrando estar na gênese de uma abordagem pela Visão Baseada nos Recursos sobre quais os recursos estratégicos não imitáveis, não substituíveis, valiosos e raros.

As redes relacionais, ou networks, têm sido amplamente examinadas, talvez mais especialmente como geradoras de novas oportunidades e para aceder a recursos, veiculando a relevância de integrar e pensar estrategicamente a rede relacional, face aos objetivos da 
TRÊS DÉCADAS DE PESQUISA EM EMPREENDEDORISMO: UMA REVISÃO DOS PRINCIPAIS PERIÓDICOS INTERNACIONAIS DE EMPREENDEDORISMO

empresa, ajustados à fase do ciclo de vida em que se encontra. Assim, surgem os trabalhos de Granovetter (1973, 1985), Burt (1992), Birley (1985) e Aldrich e Zimmer (1986). As redes veiculam uma diversidade de recursos físicos, informacionais e mesmo de reputação e legitimidade. Este é o contexto genérico em que a teoria institucional tem contribuído para os estudos de empreendedorismo.

Em suma, as bases teóricas da disciplina mostram a sua origem, mas também constituem a base sobre a qual a pesquisa é realizada. Segundo Low e MacMillan (1988) não é clara qual a teoria em empreendedorismo ou qual devia ser. Segundo Gartner (2001) não há uma teoria capaz de englobar todo o fenômeno que é estudado em empreendedorismo. Esta observação pode explicar que os acadêmicos pesquisem aspectos, ou objetos, específicos e talvez aparentemente desconexos, desde o empreendedorismo corporativo à sucessão em empresas familiares.

Objetos de estudo. Na figura 2 podemos também ver como são salientes preocupações com objetos de estudo. Por exemplo, emergem o foco com aspectos comportamentais do empreendedor (MCCLELLAND, 1961; BUSENITZ; BARNEY, 1997), com a orientação empreendedora (MILLER, 1983; LUPKIN; DESS, 1996), e a inovação (SCHUMPETER, 1934) geradora da criação de novas empresas (GARTNER, 1985). Esta análise pode ser complementada com o mapa da figura 3, onde notamos os principais temas e como se interligam na pesquisa existente. Nesta figura, em posição mais central, significando também que são mais comuns, estão os cinco temas relativos ao processo empreendedor, às formas como o ambiente externo determina o empreendedorismo, às questões metodológicas, à criação de valor e desempenho e as caraterísticas individuais e cognitivas. É neste core que se concentra a maioria da pesquisa. O foco nas características do empreendedor e no ambiente já tinha sido identificado por Low e MacMillan (1988) e Ratnatunga e Romano (1997) como o principal foco da pesquisa.

A análise do ambiente externo ultrapassa a perspectiva da ecologia populacional e levanta assuntos relacionados com todo o quadro institucional, as oportunidades, a disponibilidade de recursos (SHANE; VENKATARAMAN, 2000). A pesquisa existente já tratou algumas fontes de oportunidades e como os empreendedores conhecem as oportunidades, inclusive por meio da sua rede de relações e em experiências prévias de trabalho. Mas, a influência do ambiente externo é mais ampla que as oportunidades e os recursos (ALDRICH; MARTINEZ, 2001), no entanto, é pouco conhecido como as organizações empreendedoras reagem a alterações ambientais. Flexibilidade e adaptabilidade 
Manuel Portugal Vasconcelos Ferreira, Cláudia Frias Pinto \& Rui Mourato Miranda

permanecem como assunções não testadas de resposta das empresas empreendedoras. Curiosamente, os estudos focaram mais o processo e até a gênese das novas empresas empreendedoras, mas são mais escassos os estudos aferindo o desempenho destas empresas.

Outro conjunto de trabalhos, numa segunda linha (olhando a figura de dentro para fora) aborda temas como os fundadores, os recursos necessários, as redes e o empreendedorismo de base tecnológica. Ainda que relativamente menos centrais, estes são temas que foram bastante pesquisados. Algumas destas linhas de pesquisa têm suporte teórico mais notório, como no estudo da importância das redes sociais, as do empreendedor, as formais e informais, como pré-condição para aceder a recursos e como forma de desenvolvimento (BIRLEY, 1985; ALDRICH; ZIMMER, 1986).

No entanto, também identificamos uma diversidade de outros temas na pesquisa em empreendedorismo, com conexões mais tênues, o que foi comparado ao modelo da "garbage can" em disciplinas emergentes (ver, por exemplo, RATNATUNGA \& ROMANO, 1997). A pesquisa tem adotado grande diversidade de ideias, de metodologias, de teorias, sem que pareça emergir uma estrutura coerente e teoria própria. Pelo menos em parte, essa evidência emerge na observação dos temas periféricos (Figura 3), ou seja, os relativamente menos pesquisados e com ligações mais tênues aos restantes, no qual encontramos desde tomada de decisão, aspetos culturais, comercialização e marketing, análise de indústrias, liderança e equipes executivas, etc. Não significa que os temas não são relevantes para o contexto de empreendedorismo. Por exemplo, o empreendedorismo internacional (tema: Entry modes, international, born global) tem sido menos focado pelos acadêmicos (OVIATT; MCDOUGALL, 1994), tal como as empresas familiares ou a gestão de recursos humanos. No entanto, essa observação não deve ser desligada dos periódicos que incluímos no estudo, e importa referir que é possível que artigos com estes temas sejam publicados em periódicos especializados nas respetivas áreas disciplinares. Por exemplo, sobre empresas familiares em periódicos de family business. Na literatura em empreendedorismo internacional, por exemplo, notamos as ligações tênues com as demais áreas, o que também pode ser evidência que ainda é um tema mais específico a outras disciplinas.

É interessante que embora as previsões econômicas apontem o crescimento de algumas economias emergentes como o Brasil, Rússia, Índia e China, além de outras que incluem o México e Indonésia, a pesquisa em empreendedorismo nestes países é ainda escassa, principalmente no Brasil, Rússia e Índia (BRUTON; AHLSTROM; OBLOJ, 2008). Para os pesquisadores brasileiros essa é uma matéria relevante no sentido de desenvolverem estudos

REAd | Porto Alegre - Edição 81 - N 2 - maio/agosto 2015 - p 406 - 436 
TRÊS DÉCADAS DE PESQUISA EM EMPREENDEDORISMO: UMA REVISÃO DOS PRINCIPAIS PERIÓDICOS INTERNACIONAIS DE EMPREENDEDORISMO

para entender como se desenvolve o empreendedorismo nas economias emergentes. É possível, por exemplo, que o atual conhecimento sobre empreendedorismo, que tem um forte viés norte americano e europeu, não seja diretamente aplicável em outras realidades nacionais e institucionais. Se as economias emergentes têm características únicas (por exemplo, o ambiente institucional, a economia, a cultura, a dimensão do país) os fatores contextuais devem ser examinados para entender como impactam realmente a iniciativa empreendedora, o tipo de empreendedorismo gerado, etc., em economias emergentes (BRUTON; AHLSTROM; OBLOJ, 2008) e, assim, contribuir para entender como será o futuro do empreendedorismo nestes paísess.

Assim, identificamos evidência para a crítica que a disciplina se manteve muito baseada no estudo de fenômenos e, pelo menos em parte, mais ateórica. Ainda assim, é interessante para jovens doutorandos examinar os temas em posições periféricas e perscrutar em diferentes abordagens conceituais, como a pesquisa em empreendedorismo pode contribuir teoricamente para estes temas e como os temas podem ser integrados, coerentemente, na disciplina.

Raison d'etre da disciplina. Vários dos artigos identificados na análise de cocitações e nos temas pesquisados debruçam-se sobre a própria disciplina, a sua raison d'etre, ou domínio (GARTNER, 2001; SHANE; VENKATARAMAN, 2000; SCHILDT ET AL., 2006). Desde os trabalhos de Schumpeter que associamos o empreendedorismo a um conjunto de fenômenos incluindo a inovação, a competição e flexibilidade em contraste com as grandes empresas, à orientação para pequenos nichos de mercado, às características cognitivas e psicológicas dos empreendedores, à criação de novas empresas, à criação de empregos e, talvez mais genericamente, à atividade econômica e desenvolvimento econômico dos países. No entanto, como é que estes fenômenos e questões definem e delimitam a disciplina é menos certo. Shane e Venkataraman (2000) argumentam que empreendedorismo se prende com a descoberta e exploração de novas oportunidades, os indivíduos empreendedores e os meios de ação para explorar as oportunidades. Low e MacMillan (1988) propuseram que empreendedorismo se prende com a criação de novas empresas. Numa perspectiva idêntica, Gartner (2001) afirmou que empreendedorismo foca a organização dos recursos e criação de novas empresas. Mas, é necessária pesquisa futura delimitadora de um domínio, de um campo teórico comum definido.

Metodologias. Uma revisão por Low e MacMillan (1988) argumentou a importância de maior rigor metodológico na pesquisa em empreendedorismo. Chandler e Lyon (2000) mostraram que a disciplina de empreendedorismo tem evoluído consideravelmente movendo-

REAd | Porto Alegre - Edição 81 - N 2 - maio/agosto 2015 - p 406 - 436 
se do estudo de casos, indivíduos e análises univariadas para a adoção crescente de técnicas estatísticas multivariadas. A Evidência está na figura 3 na qual encontramos o foco nos aspectos metodológicos, manifesto nas citações frequentes a Nunally (1985), Eisenhardt (1989) e Hair et al. (1995). A sofisticação metodológica previsivelmente será capaz de melhorar a incorporação de teoria na pesquisa e os próprios periódicos exigem que os estudos empíricos sejam baseados em teoria e contenham uma contribuição teórica. A sofisticação empírica também pode contribuir para que as implicações para empreendedores e agências públicas tenham uma base conceitual forte.

Pesquisa futura pode incorporar diferentes fontes de dados, incluindo secundários, que podem permitir ultrapassar problemas de variância de método comum (Common Method Variance) que podem emergir em pesquisas por questionário. A realidade é que haverá desafios em obter dados secundários ideais e estas pesquisas possivelmente enfrentarão dificuldades como a escassez de dados relativos a pequenas e médias empresas e a novas empresas que tendem a ser pequenas e lideradas por um fundador. No entanto, esta é uma questão que também depende do nível de análise na pesquisa, que talvez se possa mover do indivíduo empreendedor para aspectos como o ambiente institucional, as fontes de recursos, as redes, a constituição de novas empresas, capital de risco, spin-offs universitárias, etc., onde há maior acesso a dados e que permitem triangulação. A realização de pesquisa empírica com amostras maiores tem sido uma tendência em Adminsitração (PHELAN ET AL., 2002) a que o campo de empreendedorismo não é imune.

Ainda que não apenas uma questão de metodologia, a pesquisa em empreendedorismo pode ter maior componente longitudinal (LOW; MACMILLAN, 1988) observando a evolução das novas empresas, o acesso a recursos, a expansão internacional, ou o insucesso no mercado. Uma das dificuldades desta linha de pesquisa prende-se com o acesso continuado à empresa e aos altos níveis de insucesso que são reportados com uma maioria das novas empresas a extinguir-se em até cinco anos após fundação. Sem estes estudos, é possível que, a pesquisa seja enviesada por uma amostra pequena de casos de sucesso e possivelmente em ambientes especialmente férteis, desconhecendo-se o que ocorre em outros casos. Há um espaço amplo de aprendizagem também no insucesso.

\subsection{Limitações e pesquisa futura}

Outras pesquisas futuras emergem das próprias limitações deste artigo. Por exemplo, restringimos o estudo a oito periódicos especializados em empreendedorismo. Embora estes sejam periódicos líderes, e com maior reputação e maior fator de impacto, não são exaustivos

REAd | Porto Alegre - Edição 81 - N 2 - maio/agosto 2015 - p 406 - 436 
TRÊS DÉCADAS DE PESQUISA EM EMPREENDEDORISMO: UMA REVISÃO DOS PRINCIPAIS PERIÓDICOS INTERNACIONAIS DE EMPREENDEDORISMO

de toda a pesquisa e vários outros periódicos na área de Administração também publicam artigos sobre empreendedorismo. Embora não vejamos motivo para que essa pesquisa seja substancialmente diferente, futuros estudos podem considerar ampliar a análise para outros periódicos. Talvez relevante seja entender o foco disciplinar, distinguindo as diferenças nas orientações teóricas, dos estudos em empreendedorismo nesses outros periódicos. Pese esta limitação subjacente, é mais atrativo o foco nos periódicos líderes, porque são estes que os autores procuram para colocar os seus trabalhos e serão, previsivelmente, os artigos com maior impacto sobre a evolução intelectual da disciplina.

Outra limitação metodológica assenta nos termos pesquisados na base ISI web of knowledge para extrair a amostra. Um leque mais amplo de termos de pesquisa permitirá outras caracterizações pelo que pesquisa futura pode, por exemplo, pesquisar por termos como innovation ou disruptive innovation, termos ligados aos trabalhos de Schumpeter. Uma alternativa seria usar todo o histórico de artigos publicados nestes periódicos, mas isso resultaria numa enorme base de dados de 4.772 artigos - cuja análise seria realisticamente inviável.

Finalmente, temos as limitações de análise. Embora muitos estudos tenham usado análises de citações e cocitações, o método não é imune a críticas e não sabemos qual o motivo que presidiu a uma dada citação - que pode ser para sustentar um argumento, complementar um trabalho ou criticar uma abordagem. As análises de citações podem ser enviesadas para os artigos mais antigos - o fato é que, outros fatores constantes, trabalhos mais antigos tendem a ser mais citados que trabalhos mais recentes. Uma discussão mais aprofundada sobre as assunções das análises de citações está disponível em Cheek, Garnham e Quan (2006). De igual modo não é perfeito o procedimento de inferir conteúdo examinando as palavras-chave fornecidas pelos autores. É um procedimento razoável, dado que os autores escolhem palavras com o propósito de identificar o conteúdo do artigo a potenciais leitores e para fins de indexação, mas não substitui uma análise de conteúdo. Pesquisa futura pode desenvolver métodos alternativos para inferir o conteúdo dos artigos.

\section{CONSIDERAÇÕES FINAIS}

A disciplina de empreendedorismo tem evoluído substancialmente ao longo das últimas duas décadas. Os progressos notam-se no objeto de estudo, que não se limita às características psicológicas dos empreendedores, na adoção de maior rigor metodológico, na procura por um campo de pesquisa específico com fundamentos teóricos aceites. Os progressos 
Manuel Portugal Vasconcelos Ferreira, Cláudia Frias Pinto \& Rui Mourato Miranda

metodológicos são usuais com a maturação das disciplinas, e a evolução de estudos de caso para trabalhos empíricos foi notada por Phelan et al. (2002) na disciplina de estratégia. Ainda assim, o nosso estudo releva que a disciplina mantêm traços de "garbage can", pautando-se por grande diversidade de objetos de estudo, que se estendem das dinâmicas e caraterísticas regionais promotoras de empreendedorismo, às empresas familiares, à inovação, ao capital de risco, ao empreendedorismo social e à organizações sem fim lucrativo, o impacto de variáveis externas, a internacionalização, dentre outros.

Apesar dos assinaláveis progressos, pelo menos em alguma medida, toda esta pesquisa ainda não parece estar bem enquadrada num domínio delimitado (GARTNER, 2001) que possamos identificar claramente como uma disciplina madura. Se o nosso objetivo aqui não é questionar a existência da disciplina, ou do campo de estudo, estas considerações emergem da grande diversidade de fenômenos estudados e perspectivas conceituais que identificamos na pesquisa existente. Talvez uma das principais vantagens de ter um domínio bem definido, com uma comunidade acadêmica que se identifica com a disciplina é, como exposto por Davidsson, Low e Wright (2001), que a pesquisa aumentará e a disciplina capturará o seu lugar inquestionável em Administração.

As disciplinas distinguem-se e definem-se por questões de pesquisa únicas, que estão fora do domínio de outras disciplinas. As disciplinas ganham status quando os estudos realizados são suportados em metodologias empíricas sofisticadas e em teoria. Uma via possível é absorver teorias de outras disciplinas e contribuir para o desenvolvimento das próprias teorias. Ainda que, não seja evidente uma teoria própria de empreendedorismo, emerge o foco diferenciador no empreendedor, na oportunidade não explorada, na importância dos recursos do empreendedor incluindo os seus recursos sociais, e no papel das redes relacionais do empreendedor. Assim, há um espaço amplo sobre o qual pesquisa futura pode construir, propondo conceitos e teorias. 
TRÊS DÉCADAS DE PESQUISA EM EMPREENDEDORISMO: UMA REVISÃO DOS PRINCIPAIS PERIÓDICOS INTERNACIONAIS DE EMPREENDEDORISMO

\section{REFERÊNCIAS}

ALDRICH, H.; MARTINEZ, M. Many are called, but few are chosen: An evolutionary perspective for the study of entrepreneurship. Entrepreneurship Theory and Practice, $v$. 25, n. 4, p. 41-56, 2001.

ALDRICH, H.; ZIMMER, C. Entrepreneurship through social networks. In Sexton, D. \& Smilor, R. (Eds.), The Art and Science of Entrepreneurship, Cambridge, MA: Ballinger, p. 3-23, 1986.

ALDRICH, H. Organizations evolving. London; Thousand Oaks, California: Sage, 1999.

ANDRES, A. Measuring academic research: How to undertake a bibliometric study, Cambridge, UK: Chandos Publishing, 2009.

BARNEY, J. Firm resources and sustained competitive advantage. Journal of Management, v. 17, n. 1, p. 99-120, 1991.

BIRLEY, S. The role of networks in the entrepreneurial process. Journal of Business Venturing, v. 1, n. 1, p. 107-117, 1985.

BOYACK, K.; BÖRNER, K. Indicator-assisted evaluation and funding of research:

Visualizing the influence of grants on the number and citation counts of research papers. Journal of the American Society for Information Science and Technology, v. 54, n. 5, p. 447-461, 2003.

BRUTON, G.; AHLSTROM, D.; OBLOJ, K. Entrepreneurship in emerging economies: Where are we today and where should the research go in the future. Entrepreneurship Theory and Practice, v. 32, n. 1, p. 1-14, 2008.

BURT, R. Structural holes: The social structure of competition. Harvard University Press, 1992.

BUSENITZ, L.; BARNEY, J. Differences between entrepreneurs and managers in large organizations: Biases and heuristics in strategic decision-making. Journal of Business Venturing, v. 12, n. 6, p. 9-30, 1997.

BUSENITZ, L.; WEST, G.; SHEPHERD, D.; NELSON, T.; CHANDLER, G.; ZACHARAKIS, A. Entrepreneurship research in emergence: Past trends and future directions. Journal of Management, v. 29, p. 285-308, 2003. 
Manuel Portugal Vasconcelos Ferreira, Cláudia Frias Pinto \& Rui Mourato Miranda

BUSENITZ, L.; PLUMMER, L; KLOTZ, A.: SHAHZAD, A.; RHOADS, K. ntrepreneurship research (1985-2009) and the emergence of opportunities. Entrepreneurship Theory and Practice, v. 38, n. 5, p. 981-1000, 2014.

CAMPOS, H.; PARELLADA, F.; PALMA, Y. Mapping the intellectual structure of entrepreneurship research: Revisiting the invisible college. Revista Brasileira de Gestão de Negócios, v. 14, n. 42, p. 41-58, 2012.

CHABOWSKI, B.; HULT, G.; KIYAK, T.; MENA, J. The structure of JIBS's social network and the relevance of intra-country variation: a typology for future research. Journal of International Business Studies, v. 41, n. 5, p. 925-934, 2010.

CHEEK, J.; GARNHAM, B.; QUAN, J. What's in a number? Issues in providing evidence of impact and quality of research(ers). Qualitative Health Research, v. 16, n. 3, p. 423-435, 2006.

CHIU, W.; HO, Y. Bibliometric analysis of tsunami research, Scientometrics, v. 73, p. 3-17, 2007.

CHUN, K.; PAK, H.; COX, R. Patterns of research output in the accounting literature: A study of the bibliometric distributions. Abacus, v. 28, n. 2, p. 168-185, 1992.

COHEN, W.; LEVINTHAL, D. Absorptive capacity: A new perspective on learning and innovation. Administrative Science Quarterly, v. 35, p. 128-152, 1990.

COOPER, A.; GIMENO-GASCON, F.; WOO, C. Initial human and financial capital as predictors of new venture performance. Journal of Business Venturing, v. 9, n. 5, p. 371395, 1994.

CORNELIUS, B.; LANDSTRÖM, H.; PERSSON, O. Entrepreneurial studies: The dynamic research front of a developing social science. Entrepreneurship Theory and Practice, v. 30, n. 3, p. 375-398, 2006.

COVIN, J.; SLEVIN, D. Strategic management of small firms in hostile and benign environments. Strategic Management Journal, v. 10, n. 1, p. 75-87, 1989.

CULNAN, M. Mapping the intellectual structure of MIS, 1980-1985: A co-citation analysis. MIS Quarterly, v. 11, n. 3, p. 341-353, 1987.

DAIM, T.; RUEDA, G.; MARTIN, H.; GERDSRI, P. Forecasting emerging technologies: Use of bibliometrics and patent analysis, Technology Forecasting and Social Change, v. 73, n. 8, p. 981-1012, 2006.

REAd | Porto Alegre - Edição 81 - No 2 - maio/agosto 2015 - p 406 - 436 
TRÊS DÉCADAS DE PESQUISA EM EMPREENDEDORISMO: UMA REVISÃO DOS PRINCIPAIS PERIÓDICOS INTERNACIONAIS DE EMPREENDEDORISMO

DAVIDSSON, P.; LOW, M.; WRIGHT, M. Editors'introduction: Low and MacMillan ten years on: Achievements and future directions for entrepreneurship research.

Entrepreneurship Theory and Practice, v. 25, n. 4, p. 5, 2001.

DÉRY, R.; TOULOUSE, J. (1996). Social structuration of the field of entrepreneurship: A case study. Canadian Journal of Administrative Sciences, v. 13, n. 4, p. 285-305, 1996.

DIODATO, V. Dictionary of Bibliometrics, Binghamton, NY: Haworth Press, 1994.

EISENHARDT, K. (1989) Building theories from case study research. Academy of Management Review, v. 14, n. 4, p. 532-550, 1989.

EVANS, D.; JOVANOVIC, B. An estimated model of entrepreneurial choice under liquidity constraints. Journal of Political Economy, v. 97, n. 4, p. 808-827, 1989.

EVANS, D.; LEIGHTON, L. The determinants of changes in U.S. self-employment, 19681987. Small Business Economics, v. 1, n. 2, p. 111-120, 1989.

FERREIRA, M. A bibliometric study on Ghoshal's managing across borders, Multinational Business Review, v. 19, n. 4, p. 357-375, 2011.

FERREIRA, M.; MIRANDA, R.; REIS, N.; PINTO, C.; SERRA, F. Pesquisa em empreendedorismo no principal periódico internacional: Um estudo bibliométrico das publicações no Journal of Business Venturing entre 1987 e 2010. Revista de Empreendedorismo e Gestão de Pequenas Empresas, v. 3, n. 1, p. 56-83, 2014.

FREEMAN, L. The development of social network analysis: With an emphasis on recent events. In J. Scott \& P. Carrington (Eds.), The SAGE Handbook of Social Network Analysis (pp. 26-39). Thousand Oaks, CA: SAGE Publications, 2011.

FRIED, V. Defining a forum for entrepreneurship scholars. Journal of Business Venturing, v. 18 , n. 1, p. 1-11, 2003.

FURRER, O.; TOMAS, H.; GOUSSEVSKAIA, A. The structure and evolution of the strategic management field: A content analysis of 26 years of strategic management research. International Journal of Management Reviews, v. 10, n. 1, p. 1-23, 2008.

GARTNER, B. (1988) Who is an entrepreneur? Is the wrong question. American Journal of Small Business, v. 12, n. 40, p.543- 556, 1988. 
Manuel Portugal Vasconcelos Ferreira, Cláudia Frias Pinto \& Rui Mourato Miranda

GARTNER, W. A conceptual framework for describing the phenomenon of new venture creation. Academy of Management Review, v. 10, n. 4, p. 696-706, 1985.

GARTNER, W. Is there an elephant in entrepreneurship? Blind assumptions in theory development. Entrepreneurship Theory and Practice, v. 25, n. 4, p. 27-39, 2001.

GARTNER, W.; DAVIDSSON, P.; ZAHRA, S. Are you talking to me? The nature of community in entrepreneurship scholarship. Entrepreneurship Theory and Practice, v. 30, n. 3, p. 321-331, 2006.

GIMENO, J.; FOLTA, T.; COOPER, A.; WOO, C. Survival of the fittest? Entrepreneurial human capital and the persistence of underperforming firms. Administrative Science Quarterly, v. 42, p. 750-83, 1997.

GRANOVETTER, M. The strength of weak ties. American Journal of Sociology, v. 78, n. 6, p. 1360-1380, 1973.

GRANOVETTER, M. Economic action and social structure: The problem of embeddedness. American Journal of Sociology, v. 91, n. 11, p. 481-510, 1985.

GRÉGOIRE, D.; MEYER, G.; DE CASTRO, J. The crystallization of entrepreneurship research DVs and methods in mainstream journals. In Bygrave, W. (Ed.) Frontiers of Entrepreneurship Research 2002, Babson College, 2002.

GRÉGOIRE, D.; NOËL, M.; DÉRY, R.; BÉCHARD, J. Is there conceptual convergence in entrepreneurship research? A co-citation analysis of frontiers of entrepreneurship research, 1981-2004. Entrepreneurship Theory and Practice, v. 30, n. 3, p. 333-373, 2006.

HAIR, J.; ANDERSON, R.; TATHAM, R.; BLACK, W. Multivariate data analysis with readings, Englewood Cliffs, New Jersey: Prentice-Hall, 1995.

HARGENS, L. Using the literature: Reference networks, reference contexts, and the social structure of scholarship. American Sociological Review, v. 65, n. 6, p. 846-865, 2000.

HARZING, A-W. Harzing Journal Quality List, thirty-eight edition, 4 February, compiled and edited by Anne-Will Harzing, 2011.

HOFER, K.; SMEJKAL, A.; BILGIN, F.; WUEHRER, G. (2010). Conference proceedings as a matter of bibliometric studies: The Academy of International Business 2006-2008.

Scientometrics, v. 84, n. 3, p. 845-862, 2010.

REAd | Porto Alegre - Edição 81 - No 2 - maio/agosto 2015 - p 406 - 436 
TRÊS DÉCADAS DE PESQUISA EM EMPREENDEDORISMO: UMA REVISÃO DOS PRINCIPAIS PERIÓDICOS INTERNACIONAIS DE EMPREENDEDORISMO

HOFSTEDE, G. Culture's consequences: International differences in work-related values. Beverly Hills, CA: Sage, 1980.

HOFFMAN, D.; HOLBROOK, M. The intellectual structure of consumer research: A bibliometric study of author cocitations in the first 15 years of the journal of consumer research. Journal of Consumer Research, v. 19, p. 505-517, 1993.

JENSEN, M.; MECKLING, W. Theory of the firm: Managerial behavior, agency costs and ownership structure. Journal of Financial Economics, v. 3, n. 4, p. 305-360, 1976.

JING, S.; QINGHUA, Z.; LANDSTRÖM, H. Entrepreneurship research in three regions-the USA, Europe and China. International Entrepreneurship and Management Journal, (ahead-of-print) 1-30 DOI 10.1007/s11365-014-0315-6, 2014.

JOVANOVIC, B. Selection and the evolution of industry. Econometrica, v. 50, p. 649-670, 1982.

KATZ, J. The chronology and intellectual trajectory of American entrepreneurship education 1876-1999. Journal of Business Venturing, v. 18, n. 2, p. 283-200, 2003.

KEUPP, M.; GASSMANN, O. The past and the future of international entrepreneurship: A review and suggestions for developing the field. Journal of Management, v. 35, n. 3, p. 600-633, 2009.

KIRZNER, I. Competition and entrepreneurship, Chicago, IL: University of Chicago Press, 1973.

KNIGHT, F. Risk, uncertainty and profit, New York: Harper, 1921.

KRAUS, S. State-of-the-art current research in international entrepreneurship: A citation analysis. African Journal of Business Management, v. 5, n. 3, p. 1020-1038, 2011.

LANDSTRÖM, H.; HARIRCHI, G.; ASTRÖM, F. Entrepreneurship: Exploring the knowledge base. Research Policy, v. 41, n. 1, p. 1154-1181, 2012.

LOW, M.; MACMILLAN, I. Entrepreneurship: Past research and future challenges. Journal of Management, v. 14, p. 139-161, 1988.

LOW, M. The adolescence of entrepreneurship research: Specification of a purpose.

Entrepreneurship Theory and Practice, v. 25, n. 4, p. 17-25, 2001.

REAd | Porto Alegre - Edição 81 - No 2 - maio/agosto 2015 - p 406 - 436 
Manuel Portugal Vasconcelos Ferreira, Cláudia Frias Pinto \& Rui Mourato Miranda

LUMPKIN, G.; DESS, G. Clarifying the entrepreneurial orientation construct and linking it to performance. Academy of Management Review, v. 21, n. 1, p. 135-172, 1996.

MCCLELLAND, D. The achieving society. Princeton, NJ: Van Nostrand, 1961.

MILLER, D. The correlates of entrepreneurship in three types of firms. Management Science, v. 29, n. 7, p. 770-791, 1983.

NEDERHOF, A.; ZWAAN, R.; DE BRUIN, R.; DEKKER, P. Assessing the usefulness of bibliometric indicators for the humanities and the social and behavioural sciences: A comparative study. Scientometrics, v. 15, p. 423-435, 2005.

NELSON, R.; WINTER, S. An evolutionary theory of economic change. Cambridge, MA: Belknap Press/Harvard University Press, 1982.

NEWMAN, M. The structure and function of complex networks. SIAM Review, v. 45, n. 2, p. 167-256, 2003.

NUNNALLY, J. Psychometric theory. New York: McGraw Hill, 1978.

OVIATT, B.; MCDOUGALL, P. Toward a theory of international new ventures. Journal of International Business Studies, v. 25, n. 1, p. 45-64, 1994.

PASADEOS, Y.; PHELPS, J.; KIM, B. Disciplinary impact of advertising scholars: temporal comparisons of influential authors, works and research networks. Journal of Advertising, v. 27, n. 4, p. 53-70, 1998.

PENROSE, E. The theory of the growth of the firm, New York, NY: John Wiley, 1959.

PFEFFER, J.; SALANCIK, G. The external control of organizations: A resource dependence perspective, New York: Harper \& Row, 1978.

PHELAN, S.; FERREIRA, M.; SALVADOR, R. The first twenty years of the Strategic Management Journal, Strategic Management Journal, v. 23, n. 12, p. 1161-1168, 2002.

PILKINGTON, A.; LISTON-HEYES, C. Is production and operations management a discipline? A citation/co-citation study. International Journal of Operations \& Production Management, v. 19, n. 1, p. 7-20, 1999. 
TRÊS DÉCADAS DE PESQUISA EM EMPREENDEDORISMO: UMA REVISÃO DOS PRINCIPAIS PERIÓDICOS INTERNACIONAIS DE EMPREENDEDORISMO

PONZI, L. The intellectual structure and interdisciplinary breadth of Knowledge Management: A bibliometric study of its early stage of development, Scientometrics, v. 55, n. 2, p. 259-272, 2002.

PORTER, M. Competitive strategy. Free Press: New York, 1980.

RAFOLS, I.; PORTER, A.; LEYDESDORFF, L. Science overlay maps: a new tool for research policy and library management. Journal of the American Society for Information Science and Technology, v. 61, n. 9, p.1871-1887, 2010.

RAMOS-RODRIGUEZ, A.; RUÍZ-NAVARRO, J. Changes in the intellectual structure of strategic management research: A bibliometric study of the Strategic Management Journal, 1980-2000. Strategic Management Journal, v. 25, n. 10, p. 981-1004, 2004.

RATNATUNGA, J.; ROMANO, C. A citation classics' analysis of articles in contemporary small enterprise research. Journal of Business Venturing, v.12, n.3, p. 197-212, 1997.

ROKAYA, M.; ATLAM, E.; FUKETA, M.; DORJI, T.; AOE, J. Ranking of field association terms using co-word analysis, Information Processing and Management, v. 44, n. 2, p. 738-755, 2008.

SCHILDT, H.; ZAHRA, S.; SILLANPAA, A. Scholarly communities in entrepreneurship research: A co-citation analysis. Entrepreneurship Theory and Practice, v. 30, n. 3, p. 399-415, 2006.

SCHUMPETER, J. The theory of economic development. Cambridge, Mass: Harvard University Press, 1934.

SCHUMPETER, J. Capitalism, socialism and democracy. Harper \& Row, New York, 1942.

SHANE, S.; VENKATARAMAN, S. The promise of entrepreneurship as a field of research. Academy of Management Review, v. 25, p. 217-26, 2000.

SHANE, S. Who is publishing the entrepreneurship research? Journal of Management, v. 23, p. 83-95, 1997.

SHANE, S. Prior knowledge and the discovery of entrepreneurial opportunities.

Organizational Science, v. 11, p. 448-469, 2000. 
Manuel Portugal Vasconcelos Ferreira, Cláudia Frias Pinto \& Rui Mourato Miranda

SMALL, H. Co-citation in the scientific literature: A new measure of the relationship between two documents. Journal of the American Society for Information Science and Technology, v. 24, p. 265-269, 1973.

SMALL, H.; GRIFFITH, B. The structure of scientific literatures (I) Identifying and graphing specialties. Science Studies, v. 4, n. 1, p. 17-40, 1974.

STEVENSON, H.; JARILLO, J. A paradigm of entrepreneurship: Entrepreneurial management. Strategic Management Journal, v. 11, p. 17-27, 1990.

STINCHCOMBE, A. Social structure and organizations. In March, J. (Ed.), Handbook of Organizations, p. 142-193, Chicago: Rand McNally, 1965.

STOREY, D. Understanding the small business sector, London, Routledge, 1994.

TAHAI, A.; MEYER, M. A revealed preference study of management journals' direct influences. Strategic Management Journal, v. 20, p. 279-296, 1999.

VENKATARAMAN, S. The distinctive domain of entrepreneurship research. In Katz, J. (Ed.) Advances in entrepreneurship, firm emergence and growth, Greenwich, CN: JAI Press, v. 3, p. 119-138, 1997.

VESPER, K. New venture strategies, Englewood Cliffs, NJ: Prentice Hall, 1990.

WASSERMAN, S.; FAUST, K. Social network analysis: Methods and applications. Cambridge, UK: Cambridge University Press, 1997.

WHITE, D.; MCCAIN, K. Visualizing a discipline: An author co-citation analysis of information science, 1972-1995. Journal of the American Society for Information Science, v. 49, p. 327-355, 1998.

WHITE, H.; GRIFFITH, B. Author co-citation: A literature measure of intellectual structure. Journal of the American Society for Information Science, v. 32, p. 163-171, 1981. 
TRÊS DÉCADAS DE PESQUISA EM EMPREENDEDORISMO: UMA REVISÃO DOS PRINCIPAIS PERIÓDICOS INTERNACIONAIS DE EMPREENDEDORISMO

Anexo. Principais temas de pesquisa: Agrupamento de palavras-chave

\begin{tabular}{|c|c|}
\hline Tema de pesquisa & frequência \\
\hline Entrepreneurial process & $(\mathrm{n}=319)$ \\
\hline Environmental and external determinants of entrepreneurship & $(\mathrm{n}=309)$ \\
\hline Value creation and performance & $(n=226)$ \\
\hline Psychological, cognitive and individual characteristics & $(\mathrm{n}=204)$ \\
\hline Methods, theories and research issues & $(\mathrm{n}=203)$ \\
\hline Entrepreneurial resources & $(\mathrm{n}=175)$ \\
\hline Founders & $(\mathrm{n}=154)$ \\
\hline Entrepreneurial networks (trust \& relational) & $(\mathrm{n}=149)$ \\
\hline High-tech entrepreneurship & $(\mathrm{n}=126)$ \\
\hline Small and Medium Enterprises & $(\mathrm{n}=82)$ \\
\hline Corporate venturing and business competition & $(\mathrm{n}=78)$ \\
\hline Industry analysis & $(\mathrm{n}=77)$ \\
\hline Cultural issues & $(\mathrm{n}=75)$ \\
\hline Organization & $(\mathrm{n}=73)$ \\
\hline Entrepreneurial opportunity & $(\mathrm{n}=66)$ \\
\hline Entry modes, international, Born-global \& MNE & $(\mathrm{n}=65)$ \\
\hline Liabilities of newness \& survival of firms & $(\mathrm{n}=61)$ \\
\hline Leadership, TMT and decision-making & $(\mathrm{n}=61)$ \\
\hline Knowledge-based view & $(\mathrm{n}=59)$ \\
\hline Human resource management & $(\mathrm{n}=47)$ \\
\hline Entrepreneurial family business & $(\mathrm{n}=46)$ \\
\hline Organizational decision-making & $(\mathrm{n}=45)$ \\
\hline Institutions and institutional entrepreneurship & $(n=34)$ \\
\hline Commercialization and marketing & $(\mathrm{n}=30)$ \\
\hline Business activities & $(\mathrm{n}=27)$ \\
\hline
\end{tabular}

$\overline{\text { Nota: Entre parenteses a frequência das palavras-chave agrupadas no tema respectivo }}$ Fonte: os autores 